\title{
Seroprevalency of Transfusion Transmitted Infections in First-Time Volunteer and Replacement Donors in Tunisia
}

Ben Jemia $\mathbf{R}^{*}$ and Gouider $\mathbf{E}$

Faculty of Medicine, Tunis University of Tunis El Manar, Rue Lakhdar, Djebal-1006 Tunis, Tunisia

"Corresponding author: Ben Jemia R, Faculty of Medicine, Tunis University of Tunis El Manar, Rue Lakhdar, Djebal-1006 Tunis, Tunisia, Tel: +21698341985; Fax: +21671 568228; E-mail: emna.gouider@gmail.com

Received date: May 25, 2014, Accepted date: Jun 08, 2015, Publication date: June 13, 2015

Copyright: $\odot 2015$ Jemia RB, et al. This is an open-access article distributed under the terms of the Creative Commons Attribution License, which permits unrestricted use, distribution, and reproduction in any medium, provided the original author and source are credited.

\section{Abstract}

Background: Replacement donors are considered as having a major risk of transmission of infections to recipients mainly by the World Health Organisation.

Study design and methods: Seroprevalency of HBV, HCV, HIV and syphilis were determined in 19,783 whole blood donations collected in the Tunisian National Blood Transfusion Center during the year $2010(12,968$ (65.55\%) replacement donations and 6815 (34.44\%) voluntary blood donations). For HBV, HCV and syphilis, we performed a univariate analysis to determine whether age, sex and type of donation were risk factors, then multivariate logistic regression, to see if these factors were independent.

Results: Mean age of donors was 30.1 years (Replacement donors 34.5 years, First Time Non Remunerated Donors 34.5 years, $p<0.001)$. The predominant age group was $30-39$ years $(35.51 \%)$ in replacement donors and $20-29$ years $(54.15 \%)$ in first time non remunerated donors. Male gender was significantly predominant $(73.00 \%$ men vs. $27.00 \%$ women, p <10-6). There were significantly more men among replacement donors $(82.27 \%$ vs. $55.38 \%, p<10-3)$. There were more women in the age groups $18-19$ and $20-29$ years.

Only one HIV seropositive donation was noted in a male first time non remunerated donor aged 18. Replacement type of donation, male sex and age were three independent risk factors for the HBs Ag carriage. For anti-HCV antibodies and TPHA, only replacement type of donation and age were found out to be risk factors and only age was independent.

Conclusion: In Tunisia, replacement blood donors were at higher risk of infection transmission, but only for hepatitis $B$.

Keywords: Blood donors; Volunteer donors; Replacement donors; Transfusion-transmitted disease; Hepatitis; HIV; Syphilis

\section{Abbreviations:}

RD: Replacement Donors; FTNRD: First Time Non Remunerated Donors; CNTS: National Center of Blood Transfusion; WHO: World Health Organisation

\section{Introduction}

Blood transfusion is a crucial therapeutic means in every health system. Satisfying the needs of blood products and ensuring blood safety, especially infectious safety, remain major challenges for blood transfusion establishments.

In Tunisia, like in many other countries, we still rely on family or replacement blood donors (RD), family members or friends, who donate blood to replace the one that has been transfused to a relative. They contribute seriously to the blood supply in this country as they represent $60 \%$ of blood donors. The World Health Organisation (WHO) recommends excluding this type of blood donors as they present a major risk of transmitting infections [1].
In order to check this data, we determined the seroprevalency of $\mathrm{HBV}, \mathrm{HCV}, \mathrm{HIV}$ and syphilis in replacement and first time non remunerated (FTNRD) Tunisian blood donors; then, we conducted a statistical study to see if age and sex were involved with any significant difference between the two types of donors.

\section{Materials and Methods}

\section{Study design and population}

It is a retrospective study including 19,783 whole blood donations collected in the Tunisian national blood transfusion center (CNTS) during the year 2010. 12,968 (65.55\%) replacement blood donations collected between January and June 2010 at fixed site at the CNTS and 6815 (34.44\%) voluntary blood donations collected between January and December 2010 at mobile collections from first time non remunerated donors (FTNRD) (27,789 blood donations provided by donors having donated earlier have been excluded from the study).

Age, sex and results of screening tests for HBV, HCV, HIV and syphilis were collected from the center written records. 
Citation: Jemia RB, Gouider E (2015) Seroprevalency of Transfusion Transmitted Infections in First-Time Volunteer and Replacement Donors in Tunisia. J Blood Disord Transfus 6: 182. doi:10.4172/2155-9864.1000282

Page 2 of 6

\section{Infectious disease testing}

Tests for serological markers of the viral agents were performed by commercial kits:

-Monolisa HBs Ag ULTRA (BIO-RAD, France) for the detection of the hepatitis B surface antigen (HBs Ag).

-HCV Murex Ag/Ab combination (Abbot Murex), detecting hepatitis $\mathrm{C}$ virus antibody (anti-HCV) and the capsid antigen.

-Genscreen ULTRA HIV Ag-Ab Assay (BIO-RAD, France), detecting the p24 antigen and antibodies for HIV-1 and HIV-2.

-Syphilitic antibodies were screened by the Treponema pallidum hemagglutination assay (TPHA Biomaghreb).

\section{Statistical analysis}

Prevalencies were calculated for 100 donors with the Epitable program of the EPI INFO software Version $6.04 \mathrm{~d}$. with confidence intervals at $95 \%$ of confidence (Fleiss quadratic method). The search for carriage risk factors was performed using SPSS for Windows version 11.5 in univariate analysis and in multivariate analysis.
Risk factors searched for were: type of donor (Replacement/ FTNRD), gender of donor (male/female), age of donor (classified in four age groups: 18-19, 20-29, 30-39, $\geq 40$ years).

For the Univariate study, we calculated the odds ratio (for the age groups, the lowest odds ratio was considered as reference) and then we conducted a multivariate logistic regression using backward stepwise method. Multivariate analysis identified factors related independently of others to carriage.

The significance level for all comparisons was set at 0.05 .

\section{Results}

\section{Demographic characteristics of blood donors}

Mean age of all the donors was 30.1 years. Replacement donors were significantly older than FTNRD (mean age: RD 34.5 years, FTNRD 34.5 years, $\mathrm{p}<0.001$ ), the predominant age group was $30-39$ years (35.51\%) followed by $20-29$ years $(33.71 \%)$ in RD and $20-29$ years $(54.15 \%)$ followed by $18-19$ (39.14\%) years in FTNRD (Figure 1 ).

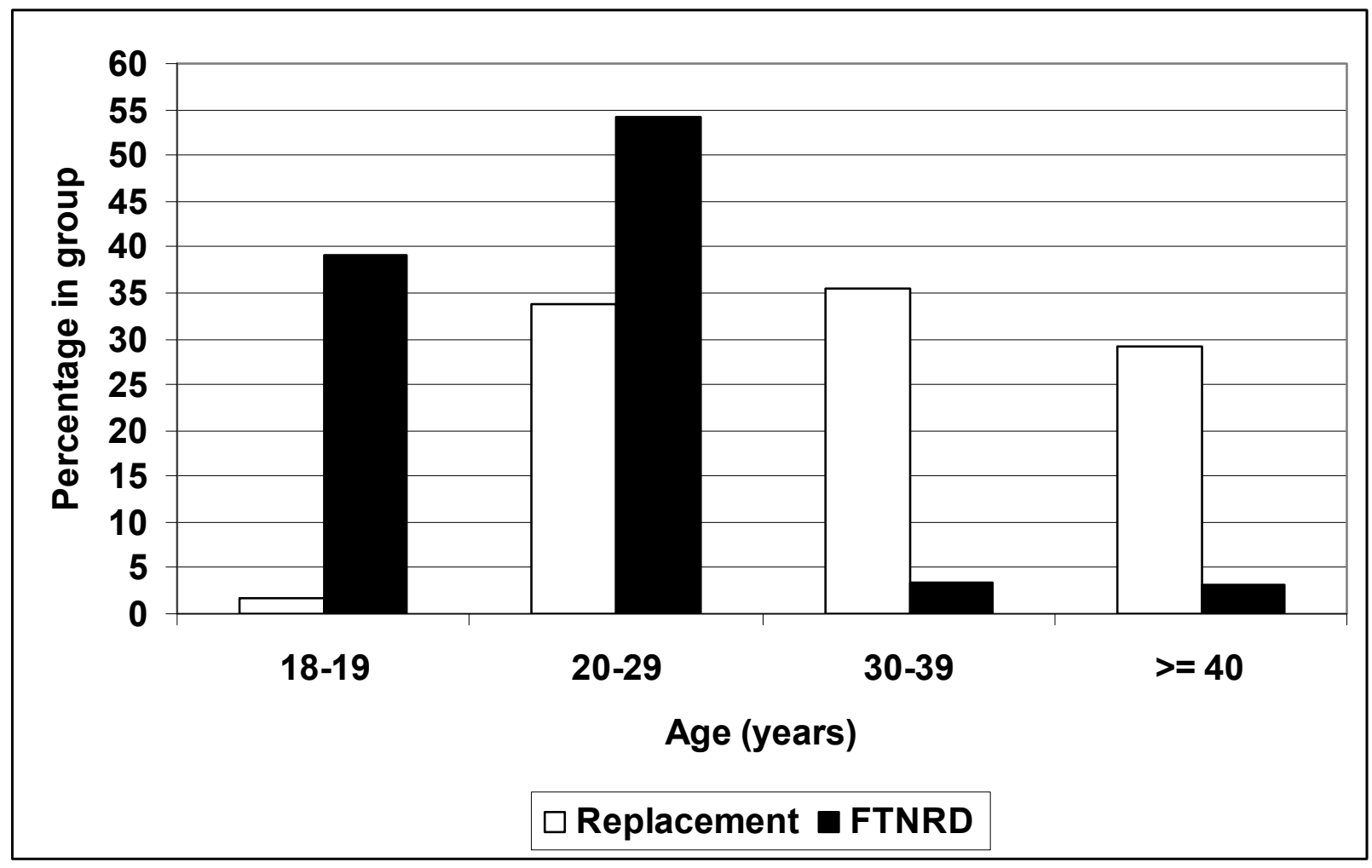

Figure 1: Distribution of donors according to age groups and type of donation.

In all blood donors, male gender was significantly predominant $(73.00 \%$ men vs. $27.00 \%$ women, $\mathrm{p}<10-6)$. There was significantly more men among RD than among FTNRD $(82.27 \%$ men in RD vs. $55.38 \%$ men in FTNRD, $\mathrm{p}<10-3$ ).
Women were more numerous in the age groups 18-19 and 20-29 years (Figure 2). 
Citation: Jemia RB, Gouider E (2015) Seroprevalency of Transfusion Transmitted Infections in First-Time Volunteer and Replacement Donors in Tunisia. J Blood Disord Transfus 6: 182. doi:10.4172/2155-9864.1000282

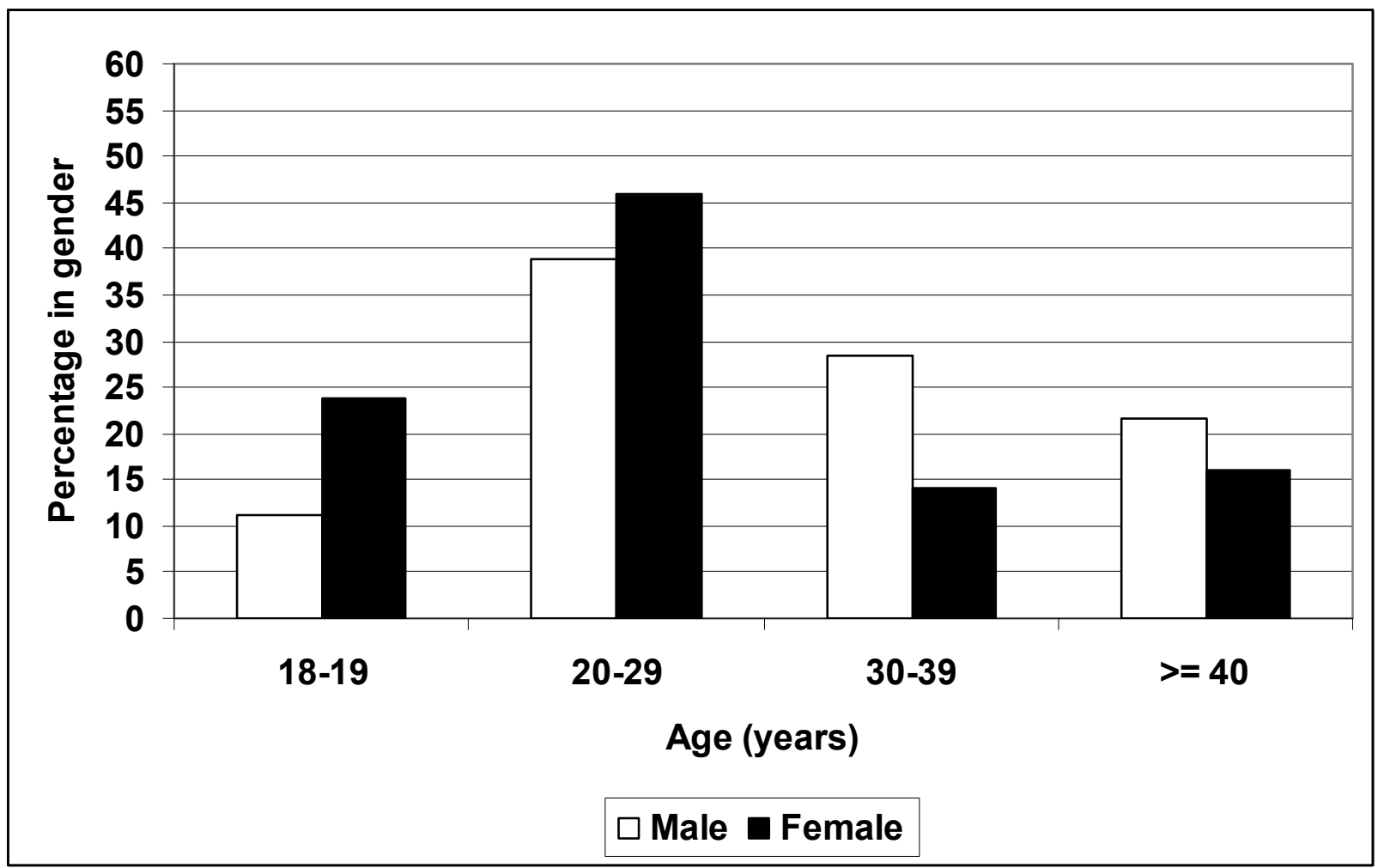

Figure 2: Distribution of donors according to age groups and sex.

\section{Seroprevalency of transfusion-transmissible infections in replacement and FTNR donors}

Only one HIV seropositive donation was noted in a male FTNR donor aged 18.

For HBV, HCV and syphilis, we performed first a univariate analysis to determine whether age, sex and type of donation were risk factors, then multivariate logistic regression, to see if these factors were independent.

Replacement type of donation, male sex and age were three risk factors for the HBs Ag carriage. For anti-HCV antibodies and TPHA, only the replacement type of donation and the age were found out to be risk factors (Table 1).

\begin{tabular}{|c|c|c|c|c|c|c|}
\hline \multirow[t]{2}{*}{ Characteristics } & \multicolumn{2}{|l|}{ HBs Ag } & \multicolumn{2}{|l|}{ Anti-HCV Ab } & \multicolumn{2}{|l|}{ TPHA } \\
\hline & $\begin{array}{l}\text { Prevalence } \% \quad(95 \% \\
\mathrm{Cl})\end{array}$ & $\begin{array}{l}\mathrm{OR}(95 \% \mathrm{Cl}) \text { and } \mathrm{p} \\
\text { value }\end{array}$ & $\begin{array}{l}\text { Prevalence } \% \\
\text { Cl) }\end{array}$ & $\begin{array}{l}\text { OR }(95 \% \mathrm{Cl}) \text { and } \mathrm{p} \\
\text { value }\end{array}$ & $\begin{array}{l}\text { Prevalence } \% \quad(95 \% \\
\mathrm{Cl})\end{array}$ & $\begin{array}{l}\text { OR }(95 \% \mathrm{Cl}) \text { and } \\
p \text { value }\end{array}$ \\
\hline Overall $(\mathrm{N}=19,783)$ & $1.46(1.30-1.64)$ & - & $0.37(0.29-0.47)$ & - & $0.13(0.09-0.20)$ & - \\
\hline \multicolumn{7}{|l|}{ Type } \\
\hline Replacement $(\mathrm{N}=12,968)$ & $1.80(1.60-2.06)$ & $2.4(1.8-3.2)$ & $0.50(0.39-0.64)$ & $3.8(1.9-7.6)$ & $0.18(0.12-0.27)$ & $4.2(1.3-14.0)$ \\
\hline FTNRD $(\mathrm{N}=6,815)$ & $0.77(0.58-1.02)$ & $P<0.001$ & $0.13(0.06-0.26)$ & $p<0.001$ & $0.04(0.01-0.14)$ & $P=0.08$ \\
\hline \multicolumn{7}{|l|}{ Gender } \\
\hline Male $(\mathrm{N}=14,443)$ & $1.66(1.46-1.89)$ & $1.9(1.4-2.6)$ & $0.40(0.31-0.53)$ & $1.5(0.8-2.6)$ & $0.14(0.09-0.22)$ & $1.3(0.5-3.2)$ \\
\hline Female $(N=5340)$ & $0.89(0.67-1.20)$ & $p<0.001$ & $0.28(0.16-0.47)$ & $P=0.19$ & $0.11(0.04-0.25)$ & $P=0.58$ \\
\hline \multicolumn{7}{|l|}{ Age group (years) } \\
\hline $18-19(\mathrm{~N}=2888)$ & $0.65(0.40-1.04)$ & 1 (reference) & $0.03(0.00-0.23)$ & 1 (reference) & $0.00(0.00-0.16)$ & 1 (reference) \\
\hline
\end{tabular}


Page 4 of 6

\begin{tabular}{|l|l|l|l|l|l|l|}
\hline $20-29(\mathrm{~N}=8,062)$ & $1.07(0.87-1.33)$ & $1.6(1.0-2.7)$ & $0.26(0.16-0.40)$ & $7.5(1.0-56.1)$ & $0.06(0.02-0.15)$ & Undefined \\
\hline $30-39(\mathrm{~N}=4,841)$ & $1.83(1.48-2.26)$ & $2.8(1.7-4.7)$ & $0.39(0.24-0.62)$ & $11.4(1.5-85.0)$ & $0.10(0.03-0.25)$ & Undefined \\
\hline$>=40(\mathrm{~N}=3,992)$ & $2.35(1.91-2.88)$ & $3.6(2.2-6.0)$ & $0.82(0.57-1.17)$ & $24.1(3.3-176.1)$ & $0.42(0.25-0.69)$ & Undefined \\
\hline & & $P<0.001$ & & $p<0.001$ & $p<0.001$ \\
\hline
\end{tabular}

Table 1: Are the type of donation, age and male gender risk factors for HBV, HCV and syphilis carriage?

According to the multivariate study, replacement type of donation, male sex and age were found as independent risk factors for the carriage of the HBs Ag. However, only age was an independent risk factor for the anti-HCV and TPHA.
Replacement type of donation was therefore an independent risk factor only for the HBs Ag (Table 2).

\begin{tabular}{|l|l|l|l|}
\hline & HBs Ag Adjusted OR (95\% Cl) and $p$ value & $\begin{array}{l}\text { Anti-HCV Ac Adjusted OR (95\% Cl) and } \mathbf{p} \\
\text { value }\end{array}$ & TPHA Adjusted OR (95\% Cl) and $p$ value \\
\hline Type & $\begin{array}{l}1.5(1.0-2.1) \\
\mathrm{P}=0.035\end{array}$ & $\begin{array}{l}1.9(0.9-4.1) \\
\mathrm{P}=0.11\end{array}$ & $\begin{array}{l}1.1(0.3-4.2) \\
\mathrm{P}=0.87\end{array}$ \\
\hline Gender & $1.5(1.1-2.1)$ & Not in the model & Not in the model \\
\hline Age group & $\mathrm{P}=0.01$ & - & - \\
\hline & $1.4(1.2-1.6)$ & $1.7(1.3-2.3)$ & $2.9(1.7-5.1)$ \\
& $\mathrm{P}<0.001$ & $\mathrm{P}<0.001$ & $\mathrm{P}<0.001$ \\
\hline
\end{tabular}

Table 2: Multivariate analysis in logistic regression: last step.

\section{Discussion}

Blood donation in Tunisia is voluntary, anonymous and unpaid. However, we distinguish:

- Replacement or family donors: donors who donate blood to compensate for the one that should be transfused to a relative or a friend.

- Volunteer donors: donors who donate blood without being compelled to do so for someone special. We distinguish in this group:

-Regular volunteer donors: who attend regularly (at least once per year) transfusion centers or blood banks to donate.

-Occasional donors: who donate blood less regularly.

-New volunteer donors: who donate for the first time.

In Tunisia, $50 \%$ of donors are replacement donors and thus contribute significantly to the blood products supply in this country.

WHO recommends countries to abandon this type of donors who would be providers of infection risk compared to volunteer donors [1]. However, in the literature, the results of the comparison of the prevalency of transfusion-transmissible infections in these two types of donors are highly disparate and do not conclude in a unanimous way to a higher risk among replacement donors [2].

Several hypotheses have been advanced to explain the higher risk in $\mathrm{RD}$. In unpaid blood donors, the main motivation to make a donation is altruism, however, some have explained the higher risk of transmission of infection in $\mathrm{RD}$ by the pressure that makes them hide risk behaviors, so they escape the exclusion during the pre-donation medical screening. In a Greek study based on a questionnaire to identify motivators and reluctance to donate blood, $5.3 \%$ of donors admitted having hidden data during pre-donation medical screening. $3.4 \%$ of them were volunteer donors and $7.1 \%$ were RD $(\mathrm{p}<0.001)$. $80 \%$ of these have admitted that they had this behavior to be sure that the blood needs of their parents are insured [3]. Others have suggested the possibility that some $\mathrm{RD}$ may be paid donors submitted by the patient's family members as RD [4]. In volunteer donors, the main motivation to make a donation is altruism [5-8], which makes them safer donors. Nevertheless, a Brazilian study showed that this is not always the case: VD motivation may be looking for free serological tests screenings [9]. In Brazil, HIV seroprevalency was significantly higher in VD [10] and it has been shown that the cause would be seeking for free HIV testing with faster results [9]. It should be noted that in Tunisia there is a center for free and anonymous HIV screening; however its role in limiting this behavior in blood donors still needs to be evaluated.

Comparing the seroprevalency of transfusion transmissible infections in $\mathrm{RD}$ and $\mathrm{VD}$ was the subject of numerous studies worldwide [4,11-20] and the results were different depending on the serological marker studied and countries. Many studies have been criticized for having found a higher seroprevalency in RD compared to VD without taking into consideration the status of the donor: new VD or regular VD (regular VD can skew the results as they had serological tests earlier) nor the heterogeneity of age and sex of the two donor groups compared $[2,12]$. These factors are all selection bias. For two comparable groups, donors should be at their first donation, adjusted for age and sex and with confirmed positive serology.

Voluntary donations included in this study come from donors who donate for the first time (this information has been taken from the donor during the medical selection, and that cannot be verified in the 
computerized data since there is no unique identifier for each donor). On the other hand, we know that replacement donors are rarely regular donors. We can therefore consider for the two groups studied that a donation corresponds to a new donor.

Our results showed a statistically significant male predominance in all blood donors (men $73 \%$, women $27 \%, \mathrm{p}<10-6$ ). This result has been widely found in other studies where blood donors were more frequently male [21-23]. Males were significantly more common among RD (male $82.27 \%$, female $17.73 \%, \mathrm{p}<0.001$ ) but not in VD (male 55.38\%, female $44.62 \%$ ). Male predominance among RD was found in other studies [3] and may be due to cultural reasons: in case of need for blood donation by a family member, it is rather the men who volunteer. Voluntary donors in our study were collected in the mobile site, and therefore it is the blood center that "goes to them" which could explain the lack of significant difference between the two sexes.

Women were more numerous in the age groups 18-19 and 20-29 years. This result can be explained by a greater interest among young women in blood donation probably as a sign of emancipation.

Replacement donors were significantly older than FTNRD (mean age: RD 34,5 years, FTNRD 34.5 years, $\mathrm{p}<0.001$ ), the predominant age group was $30-39$ years $(35.51 \%)$ followed by $20-29$ years $(33.71 \%)$ in $\mathrm{RD}$ and $20-29$ years (54.15\%) followed by $18-19$ (39.14\%) years in FTNRD.

In the United States, Europe and India, it was shown that VD belonged to younger age groups $[22,24,25]$. In this study, many VD were recruited from high schools, universities, colleges and vocational training centers which may partly explain their young age. We can also speculate that the Tunisian youth are more motivated by voluntary donation. In both sexes, group age 20-29 years was predominant, it included $38.82 \%$ of male donors and $45.99 \%$ of female donors.

\section{Seroprevalency of transfusion-transmissible infections in RD and VD}

Only one HIV positive donation was noted in a volunteer donor, which is consistent with the national epidemiological data on this virus.

The seroprevalency of HBV, HCV and syphilis were significantly higher in replacement donors as compared to voluntary donors (Table $1)$.

Statistical analysis showed that age, male sex and replacement donor type were independent risk factors for carrying the $\mathrm{HBs} \mathrm{Ag}$ (Tables 1 and 2). In the literature, the male sex is a known risk factor for carriage of HBsAg $[26,27]$ and other serological markers of HBV $[28,29]$, it can be explained by a higher frequency of risk behaviors in men. In a study of 9486 Tunisian volunteers, male sex rises significantly the risk of anti-HBc and $\mathrm{HBs} \mathrm{Ag}$ positivity and chronic $\mathrm{HBV}$ infection [27]. Age is logically a risk factor of carrying the $\mathrm{HBsAg}$. Indeed, one subject is more likely to have HBV that he is older and $\mathrm{HBs} \mathrm{Ag}$ persists long after the infection. This result is found in other studies $[4,26]$.

Tunisia is a country of medium endemicity for HBV [30]. The study of risk factors in the Tunisian population showed that the presence of a family member infected with $\mathrm{HBV}$, increases the risk of positivity of $\mathrm{HBs} \mathrm{Ag}$, anti-HBc $\mathrm{Ab}$ and chronic infection virus. A hypothesis arises then: the fact that members of the same family volunteer to make a donation to a parent and since this virus has an average endemicity in Tunisia, may explain the fact that replacement donor type is an independent risk factor of $\mathrm{HBs} \mathrm{Ag}$ carriage in blood donors.

In univariate analysis, age and replacement donor type were found out to be risk factors for carrying anti-HCV $\mathrm{Ab}$. In multivariate analysis, only age was an independent risk factor. Tunisia has a low endemicity for HCV [31,32]. Age was found out to increase the risk of carrying anti-HCV in the general population of Tunisia [9]. Male sex was not a risk factor and this is consistent with the results of a study [31] that found no difference in the prevalence of HCV in the general population according to sex.

The same study [31] found no significant difference between the prevalency of HCV patients in family contact with the virus seropositive members, and that in the entire study population.

Another Tunisian study conducted among a highly endemic area of $\mathrm{HCV}$ in a general population [32] shows that only antecedents of intravenous injections or invasive procedures were significantly associated with risk of HCV seropositivity. Risk factors are essentially iatrogenic.

Finally for TPHA, in univariate analysis, age and replacement donor type were found out to be risk factors for carrying this marker. In multivariate analysis, only age was an independent risk factor. It is expected that age is a risk factor independent of the positive TPHA; given that this marker is a serological scar with any person entering in contact with T. pallidun bacteria, whether this sickness evolves or is cured and that the older one gets, the more one may catch this infection.

In conclusion, replacement donors were blood donors at risk as stipulated by WHO, but only for hepatitis B in Tunisia. Further studies need to be done in order to see if this result is related to the endemicity of the HBV virus in this country.

Policy to have $100 \%$ voluntary donors has to be adopted to improve transfusion safety. However, the total exclusion of replacement donors (who represent $50 \%$ of donors) would affect self-sufficiency. Thus, means of recruitment and retention of volunteer donors should be put in place.

\section{References}

1. http://www.who.int/bloodsafety/publications/ UniversalAccesstoSafeBT.pdf.

2. Allain JP (2011) Moving on from voluntary non-remunerated donors: who is the best blood donor? $\mathrm{Br} J$ Haematol 154: 763-769.

3. Marantidou O, Loukopoulou L, Zervou E, Martinis G, Egglezou A, et al. (2007) Factors that motivate and hinder blood donation in Greece. Transfus Med 17: 443-450.

4. Sultan F, Mehmood T, Mahmood MT (2007) Infectious pathogens in volunteer and replacement blood donors in Pakistan: a ten-year experience. Int J Infect Dis 11: 407-412.

5. Bednall TC, Bove LL (2011) Donating blood: a meta-analytic review of self-reported motivators and deterrents. Transfus Med Rev 25: 317-334.

6. Hupfer ME, Taylor DW, Letwin JA (2005) Understanding Canadian student motivations and beliefs about giving blood. Transfusion 45 : 149-161.

7. Sojka BN, Sojka P (2008) The blood donation experience: self-reported motives and obstacles for donating blood. Vox Sang 94: 56-63.

8. Bani M, Strepparava MG (2011) Motivation in Italian whole blood donors and the role of commitment. Psychol Health Med 16: 641-649. 
Citation: Jemia RB, Gouider E (2015) Seroprevalency of Transfusion Transmitted Infections in First-Time Volunteer and Replacement Donors in Tunisia. J Blood Disord Transfus 6: 182. doi:10.4172/2155-9864.1000282

Page 6 of 6

9. Goncalez TT, Sabino EC, Murphy EL, Chen S, Chamone DA, et al. (2006) Human immunodeficiency virus test-seeking motivation in blood donors, São Paulo, Brazil. Vox Sang 90: 170-176.

10. Barreto CC, Sabino EC, Gonçalez TT, Laycock ME, Pappalardo BL, et al. (2005) Prevalence, incidence, and residual risk of human immunodeficiency virus among community and replacement first-time blood donors in São Paulo, Brazil. Transfusion 45: 1709-1714.

11. Batina A, Kabemba S, Malengela R (2007) [Infectious markers among blood donors in Democratic Republic of Congo (DRC)]. Rev Med Brux 28: 145-149.

12. Allain JP, Sarkodie F, Asenso-Mensah K, Owusu-Ofori S (2010) Relative safety of first-time volunteer and replacement donors in West Africa. Transfusion 50: 340-343.

13. Loua A, Nze Nkoure G (2010) Relative safety of first-time volunteer and replacement donors in Guinea. Transfusion 50: 1850-1851.

14. Diarra A, Kouriba B, Baby M, Murphy E, Lefrere JJ (2009) HIV, HCV, $\mathrm{HBV}$ and syphilis rate of positive donations among blood donations in Mali: lower rates among volunteer blood donors. Transfus Clin Biol 16: 444-447.

15. Mbanya DN, Tayou C (2005) Blood safety begins with safe donations: update among blood donors in Yaounde, Cameroon. Transfus Med 15: 395-399.

16. Garg S, Mathur DR, Garg DK (2001) Comparison of seropositivity of $\mathrm{HIV}, \mathrm{HBV}, \mathrm{HCV}$ and syphilis in replacement and voluntary blood donors in western India. Indian J Pathol Microbiol 44: 409-412.

17. Sharma RR, Cheema R, Vajpayee M, Rao U, Kumar S, et al. (2004) Prevalence of markers of transfusion transmissible diseases in voluntary and replacement blood donors. Natl Med J India 17: 19-21.

18. Matee MI, Magesa PM, Lyamuya EF (2006) Seroprevalence of human immunodeficiency virus, hepatitis B and $C$ viruses and syphilis infections among blood donors at the Muhimbili National Hospital in Dar es Salaam, Tanzania. BMC Public Health 6: 21.

19. Panda M, Kar K (2008) HIV, hepatitis B and C infection status of the blood donors in a blood bank of a tertiary health care centre of Orissa. Indian J Public Health 52: 43-44.

20. Ameen R, Sanad N, Al-Shemmari S, Siddique I, Chowdhury RI, et al. (2005) Prevalence of viral markers among first-time Arab blood donors in Kuwait. Transfusion 45: 1973-1980.
21. Loua A, Nze Nkoure G (2010) Relative safety of first-time volunteer and replacement donors in Guinea. Transfusion 50: 1850-1851.

22. Sougat R, Zile S, Banerjee A (2005) Psychosocial Variables of Voluntary Blood Donors at Blood Bank of a Medical College. MJAFI 61:130-132.

23. Orton SL, Virvos VJ, Williams AE (2000) Validation of selected donorscreening questions: structure, content, and comprehension. Transfusion 40: $1407-1413$

24. Sullivan MT, Umana WO, Williams AE, Bianco CE (2000) Donation incentives provided by blood centers and blood drive sponsors in the US. Transfusion 40: 35-36.

25. Kandle SK, Ghatole MP, Jahagirdar (2001) Behavioural risk factors for acquisition of HIV infection in voluntary blood donors in Solapur. Ind Med Gaz 9: 41-44.

26. Triki H, Said N, Ben Salah A, Arrouji A, Ben Ahmed F, et al. (1997) Seroepidemiology of hepatitis B, C and delta viruses in Tunisia. Trans R Soc Trop Med Hyg 91: 11-14.

27. Ben-Alaya-Bouafif N, Bahri O, Chlif S, Bettaieb J, Toumi A, et al. (2010) Heterogeneity of hepatitis $\mathrm{B}$ transmission in Tunisia: risk factors for infection and chronic carriage before the introduction of a universal vaccine program. Vaccine 28: 3301-3307.

28. Katsoulidou A, Paraskevis D, Magiorkinis E, Moschidis Z, Haida C, et al. (2009) Molecular characterization of occult hepatitis B cases in Greek blood donors. J Med Virol 81: 815-825.

29. Christensen PB, Titlestad IL, Homburg KM, Georgsen J, Kristensen T (2001) Hepatitis B core antibodies in Danish blood donors: a surrogate marker of risk behaviour. Vox Sang 81: 222-227.

30. Bahri O (2008) EpidÃ@miologie de lâ€ ${ }^{\mathrm{mx}} \mathrm{h} \tilde{A} \odot$ patite virale B en Tunisie. Med Maladies Infect 38:192.

31. Mejri S, Salah AB, Triki H, Alaya NB, Djebbi A, et al. (2005) Contrasting patterns of hepatitis $\mathrm{C}$ virus infection in two regions from Tunisia. J Med Virol 76: 185-193.

32. Ben Alaya Bouafif N, Triki H, Mejri S, Bahri O, Chlif S, et al. (2007) A case control study to assess risk factors for hepatitis $\mathrm{C}$ among a general population in a highly endemic area of northwest Tunisia. Arch Inst Pasteur Tunis 84: 21-27. 